\title{
Reconsideration of Invasive Technique for Occlusal Fissure Before Fissure Sealant
}

\author{
Yoshishige Yamada $^{1 *}$ and Yuichi Kimura ${ }^{2}$ \\ ${ }^{1}$ Division of Operative Dentistry, Department of Conservative Dentistry, Ohu University School of Dentistry, Fukushima, Japan \\ ${ }^{2}$ Division of Endodontics, Department of Conservative Dentistry, Ohu University School of Dentistry, Fukushima, Japan
}

*Corresponding author: Yoshishige Yamada, Division of Operative Dentistry, Department of Conservative Dentistry, Ohu University School of Dentistry, 31-1 Misumido, Tomita-machi, Koriyama-city, Fukushima 963-8611, Japan

\begin{abstract}
Fissure sealant is one of effectual method for prevent occlusal caries. Therefore, removing contaminated organic debris and plaque was important process to attain sufficient sealant retention. The aim of this study was revaluated the cleaning method and invasive technique to an occlusal fissure. Twenty-four teeth with deep fissure were used in this study and 15 teeth were cleaned by finger spreader, bristle brush and ultrasonic scalar, respectively. Remain 9 teeth were prepared fissure groove using three kinds of minimal intervention burs (BR-48, CD-50F and CD-53F). The ratio of remaining debris by fingers spreader, bristle brush and ultrasonic scalar were $35 \%, 65 \%, 25 \%$ respectively. In contrast, each fissure with invasive technique was not observed residual debris. The average preparative fissure groove by BR-48, CD-50F, CD-53F were $1.38 \mathrm{~mm}, 1.40 \mathrm{~mm}$ and $0.76 \mathrm{~mm}$ in width, and $1.58 \mathrm{~mm}, 1.66 \mathrm{~mm}, 1.18 \mathrm{~mm}$ in depth, respectively. From these results, invasive technique as fissure pretreatment before acid etching might be effective to success for good fissure sealant retention for a deep and narrow fissure and a CD-53F bur was most less preparative sound enamel.
\end{abstract}

Keywords: Fissure cleaning; invasive technique; fissure sealant

\section{Introduction}

Immature permanent teeth have a risk of occurring dental caries. Especially the percentage of occlusal pit and fissure caries is over $80 \%$ of all caries in immature permanent teeth [1] and Carlos JP et al. reported that a high percentage of these occlusal lesions occurred the caries in the first 3 years after tooth eruption [2]. Dental plaques and organic debris are easy to accumulate in a pits and fissure of occlusal surface in immature young permanent teeth, and those plaque and debris were hard to remove from pit and fissure completely by ordinal cleaning method such as using low speed of rotary tooth brush. Therefore, a technique by capping of fissure with fissure sealant is widely used in ordinal dental clinic for preventing occlusal caries. However, fissure sealants are occasionally removed out partially or totally from fissure for a long term of retention. Complete or partial fissure sealant retention after 8-10 years was reported by some studies [3-5]. The main reason of them seems that fissure sealants are not able to penetrate into whole of fissure for the characteristic of narrow fissure and prevention by dental plaques remaining into a bottom of pits and fissure.
Therefore, complete removal of debris and plaque are important factor for success of fissure sealant. Although conventional technique with rotary brush was commonly used by clinical dentist, there is a possibility of remaining dental plaque or organic debris in a pits and fissure with this treatment. The shape of fissure groove might influence on disturbing fissure cleaning. Because fissure are deep and narrow in immature molar teeth typically and it is hard to attach cleaning instrument to those debris and they are staying in the bottom of fissure for long period Moreover deep and narrow shape of fissure is disadvantage for penetrating of fissure sealant into whole of fissure groove. Therefore some researchers insist that invasive technique as enamel pre-treatment by fissure bur [6-9], air abrasion [10,11] or laser [12,13] before enamel etching and fissure sealing are necessary to success of cleaning of pits and fissure and penetration of fissure sealant sufficiently. However, these invasive techniques are not widely acceptable for young teeth treatment and there has still discussed whether invasive pre-treatment is necessary for fissure sealants or not [14-17]. Therefore, this study 
is investigated that the debris removing ability from noninvasive pit and fissure were using several kinds of cleaning methods such as conventional rotary brush, ultrasonic scalar, chemically agent. Furthermore, invasive techniques as a fissure pre-treatment were also investigated using several minimal intervention burs.

\section{Materials and Methods}

\section{Sample corrected and preparation}

Twenty-four extracted human permanent molar and wisdom teeth with deep pit and fissure were used in this study. Following an approval of use for this study by the patients, those teeth had checked their depth of fissure by dental photography and adapted similar condition of fissure were used in this study. Furthermore, they had no caries in occlusal surface. Before research, all teeth were cleaned by brushed and washed with distilled water and stored at room temperature.

\section{Application of artificial organic debris into fissure groove}

To specific valuation of removing debris ability, each fissure of all experimental teeth was filled with artificial organic debris. The organic debris was prepared according to a previous report [18]. It contained $20 \%$ of Liquitex (Liquitex Co., USA), 30\% of Starch gruel (Fueki-ko, Fueki Co., Yao, Japan), 30\% of Poster color (Sakura Co., Osaka, Japan), and finally $20 \%$ of solid food fragments for rats (MR-stock, Nihon-Nosan Co., Yokohama, Japan) originally used for animal feed. All ingredients were mixed together to simulate a clinical debris condition. All specimens were then stored in a moist chamber until start study.

\section{Group classification}

All specimens were classified into 6 groups at randomly according to the difference of cleaning method or fissure pretreated burs. Each 5 teeth were elected in group 1 to group 3 respectively (15 teeth) and those teeth were evaluated several cleaning methods without fissure invasive technique. Group1 was cleaned fissure by hand instrument (finger spreader). Group 2 was used bristle brush to fissure cleaning. Group3 was performed fissure cleaning by ultrasonic scalar. Remaining 9 teeth were divided into 3 groups (Group4 to 6) in each 3 teeth. These three groups were applied invasive technique using several types of fissure preparative burs. The detail of this classification was shown in Table 1.

Table 1: Classification of each group.

\begin{tabular}{|c|c|c|}
\hline Group & & Experimental Equipment \\
\hline 1 & Noninvasive technique & finger spreader \\
\hline 2 & Noninvasive technique & Bristle Brush \\
\hline 3 & Noninvasive technique & Ultrasonic scalar \\
\hline 4 & Invasive technique & BR-48 \\
\hline 5 & Invasive technique & CD50F \\
\hline 6 & Invasive technique & CD53F \\
\hline
\end{tabular}

\section{Experimental Procedure for noninvasive fissure}

In Group 1, fissures were cleaned with finger spreader (Mani Inc Tochigi, Japan). The fissures were gently excavated with a 15size flare finger spreader using a vibratory motion and rinsed with water spray. This process was continued until the debris was removed completely from the fissure groove (Figure 1a). In Group 2, fissures were cleaned by pointed bristle brush (Merssage brush CA, YDM Co, Tokyo, Japan) with water spray. Bristle brush was setting in a low-speed handpiece (550 cycles per minute) and leaning procedure was performed for 30 seconds. All teeth were then dried with oil-free compressed air for 20 seconds and subjected to the following investigations (Figure 1b). In Group 3, fissures were cleaned with ultrasonic scalar with thin tip (ENAC, SC point 4, OSADA Inc Tokyo, Japan) under water spray condition. Scalar head were touched and moved with the fissure groove gently and continue procedure until artificial organic debris removing (Figure 1c). Even organic debris was not removed completely, cleaning procedure using above each method was stopped within 30 seconds. Then each fissure was observed by stereomicroscope to check the ratio of residual debris.

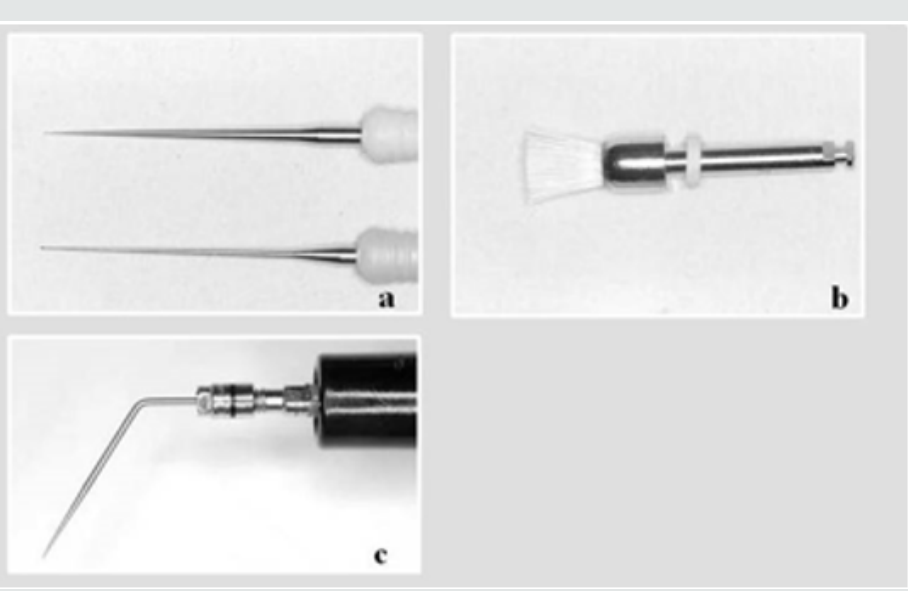

Figure 1: The instruments for fissure cleaning. 


\section{Fissure preparation for invasive technique}

Remain 15 teeth were used for invasive technique. After each fissure groove were washed, then fissure groove was prepared by three types of diamond burs. Type 1 and type 2 were small round diamond burs (BR-48 and CD-50F). Type 3 (CD-53F) were fissure type diamond bur. These all burs were produced for Minimal Intervention (MI) and are especially designed to prepare the cavity minimally as possible. These burs were connected with high speed hand piece and keep the speed as a $3000 \mathrm{rpm}$ during fissure preparing procedure (Figure 2).

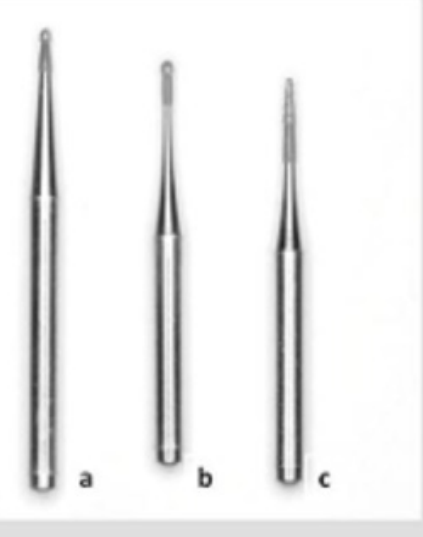

\section{a: BR-48F \\ b: CD-50F \\ c: CD-53F}

Figure 2: The instruments for fissure invasive technique.

\section{Stereoscope and SEM observation of invasive fissure}

To verify the surface characteristics, each 3 teeth in group 4 and group 5 (total 6 teeth) were selected randomly and fissure condition after invasive technique were examined using a stereomicroscope (SMZ-10, Nikon, Tokyo, Japan). Following stereomicroscopic observation, and then followed by scanning electron microscopic (SEM) examination. For SEM examination, specimens were dehydrated with a graded series of aqueous ethanol $(70 \%, 80 \%$, $90 \%$, and $100 \%$ ethanol) for 24 hours in each solution, dried with liquid $\mathrm{CO}_{2}$ using a critical point dryer device (JCPD-3, JEOL, Tokyo, Japan), coated with a platinum layer to a thickness of $15 \mu \mathrm{m}$, and observed by SEM (JSM-T220A, JEOL) at $15 \mathrm{kV}$.

\section{Results}

The evaluation of each fissure preparation by several kinds rotary bur

Figure 3 showed the condition of after pretreated fissures in invasive technique groups by stereoscopic observation. There was not revealed an abnormality mentioned such as a tooth fracture, tooth crack in all teeth. Scanning electric microscopic observation indicated that the pretreated fissure by the bur of CD-53F made most shallow and narrow fissure shape in three kind's diamond burs (Figure 4). The width of invasive fissure of BR-48F, CD-50F, $\mathrm{CD}-53 \mathrm{~F}$ were $1.38 \mathrm{~mm}, 1.40 \mathrm{~mm}, 0.76 \mathrm{~mm}$ respectively. The average of depth of invasive fissure of BR-48F, CD-50F and CD-53F were $1.58 \mathrm{~mm}, 1.66 \mathrm{~mm}, 1.18 \mathrm{~mm}$ respectively. Total results by fissure preparation by each diamond bur indicate in Table 2 . The ratio of residual debris by each cleaning method both noninvasive fissures and invasive fissures. In the groups of normal fissures showed 25 $\%$ of debris was residue in ultrasonic scalar groups. In contrast, $35 \%$ and $65 \%$ debris were not removed out from fissure by finger spreader and bristle brush, respectively. In 3 gropes with invasive technique to fissure, all debris was removed completely from fissures (Table 3).
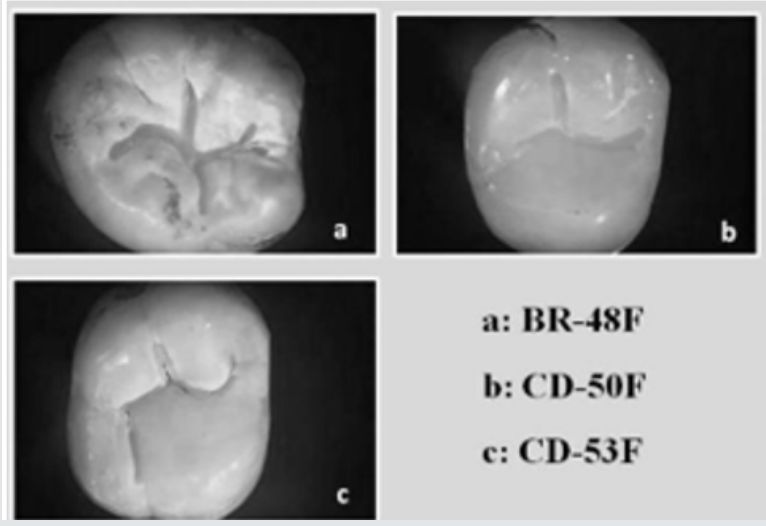

a: BR-48F

b: CD-50F

c: CD-53F

Figure 3: Stereo-scope observation of fissure groove after invasive technique. 

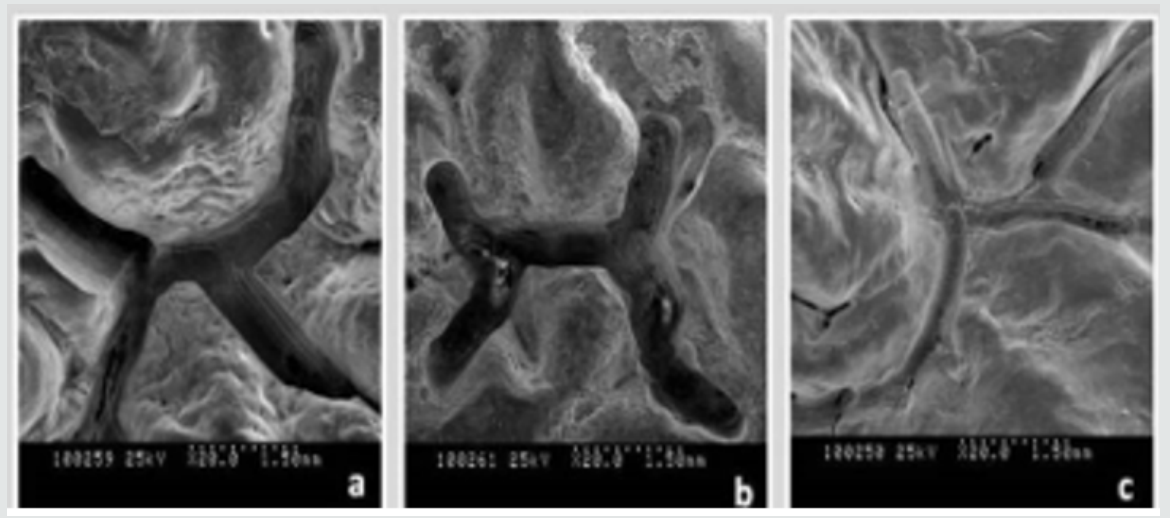

Figure 4: SEM observation of fissure groove after invasive technique.

Table 2: The mean width and depth of each fissure groove after invasive technique.

\begin{tabular}{|c|c|c|c|}
\hline Diameter (mm) & BR-48 & CD-50F & CD-53F \\
\hline Width & 1.38 & 1.40 & 0.76 \\
\hline Depth & 1.58 & 1.66 & 1.18 \\
\hline
\end{tabular}

Table 3: The ratio of residual debris by each cleaning method.

\begin{tabular}{|c|c|c|c|c|c|}
\hline G1 & G2 & G3 & G4 & G5 & G6 \\
\hline $35 \%$ & $65 \%$ & $25 \%$ & $0 \%$ & $0 \%$ & $0 \%$ \\
\hline
\end{tabular}

\section{Discussion}

To attain fissure sealant, penetrate into pit and fissure completely, the process of fissure cleaning that cause free of gross plaque and debris is important key for success of fissure sealant application. This study demonstrated that several fissure cleaning techniques using finger spreader, bristle brush and ultrasonic scalar, had not success of dental organic debris removing completely in non-inversed fissure. Remaining organic debris was mainly present on the deep narrow fissure wall and bottom of the fissure groove. These results supported that previous several similar researches that compared with both bristle brush cleaning and mechanical fissure preparative cleaning. They suggested that remaining debris and pellicle were not removed from the bases of fissures by routine cleaning and etching procedures [19-21]. Therefore the reason of remaining debris of noninvasive fissure groups in this study should be the entrance to shallow and wide groove of fissure were easy to remove debris by ordinal cleaning instruments, conversely the deep fissure wall and bottom of fissure groove were not able to attack by cleaning instrument directly. Thereby many organic debris were not removing from fissure and remaining deep side fissure wall and bottom of groove even carried out several fissure cleaning techniques using finger spreader, rotary bristle brush and ultrasonic scalar. Many cases of these phenomenon were occurred by not only relate fissure depth, but also fissure width.

These types of fissure were inhibiting fissure cleaning effectiveness, and it cause insufficient etching agent and sealant penetration, and consequently reducing adaptation ability and easy to lack of retention of sealant are occurred. From this evidence, invasive technique as a fissure pre-treatment was effectiveness to both fissure cleaning and sealant penetration. Many researchers proposed that mechanical invasive technique has good advantage for fissure sealant retention [22,23]. The result of several in vitro studies on the invasive technique with mechanical preparation has indicated that the risk of microleakage is reduced when the fissure is preventively enlarged with rotating burs [24-26]. Shapira and Eidelman have shown higher retention rate in vivo with the use of a \#1 round steel bur at low speed after 6 year, compared to non-mechanically prepared fissures $[27,28]$. Lygidakis et al. suggested their clinical study in observed for four years that the mechanical preparation of occlusal surface offer sealant retention [29]. Even these studies have demonstrated, still several researchers insist that invasive techniques were not necessary for fissure sealant application. Blackwood JA et al. reported that there was no significant difference in microleakage between the fissure cleaning with traditional pumice prophylaxis technique, fissure invasive technique and air abrasion technique [30]. However, its studies were evaluated by microleakage test using thermal cycling procedure within dwelling 500 cycles. Previous Yamada et al compared sealing ability of fissure sealant both Carisolv-and bristle brush-treated using microleakage test with 400 cycles thermal cycling [18]. Their result demonstrated that the fissure treated with bristle brush showed remaining organic materials in the bottom of groove. However, the results of microleakage tests were not specific difference both the group of removing debris completely and the group of remaining debris in bottom of the fissure.

They discussed the possibility of that the fissure sealant may have maintained a high sealing effectiveness to the marginal side wall even debris was not removed and remaining on the deep side wall in the fissure during microleakage test procedure. Therefore, microleakage test may not be a reliable evidence for the decision whether fissure pretreatment before etching and fissure sealant application is necessary or not. Accordingly sealing force of sealant was significantly reduce according passage of time and this situation might has a possibility of causing occlusal caries when it 
is occurred the detach or fracture of fissure sealant, and the debris which are contaminate several bacteria penetrate into bottom of the fissure. Although invasive technique is a good method for sealant retention, this technique should not necessary to transact for all pit and fissure. It must be selected for only hardness to debris remove completely by ordinal technique such as bristle brush and prophylaxis paste and prepared for only broad narrow fissure sharp fissures. De Craene et al. has also similar suggestion, they proposed that in a tooth with open fissures, not suspected of being carious, a prophylactic treatment for non-invasive pit-and-fissure sealing technique should be chosen, by contrast in case of deep and narrow fissures that are discolored and suspected of being carious, the invasive pit-and-fissure sealing technique should be chosen [22]. Welbury et al. reported that purposeful invasive technique just to widen the base of a fissure in a sound tooth is an invasive technique, which disturbs the equilibrium of the fissure system and exposes a child unnecessarily to the use of a handpiece or air abrasion [30]. Therefore, they insisted that invasive technique for occlusal fissures was not necessary and undesirable method. To resolve this doubtful problem, invasive technique must be performed most minimal preparation as possible.

This study was also investigated the invasive technique, then evaluated the instruments for fissure pretreatment both fissure type and round head diamond point bur which were produced for minimal intervention. Present results demonstrated that round head diamond point bur made causing unacceptable width and depth fissure sharp, because it seems round head diamond bur was smoothly moving and control was not easy to keep a fissure external form consequently fissures became more wide and deeper than what was assumed. Conversely, fissure type of diamond bur caused minimal fissure groove and it might be acceptable depth and width of them. This research proposed that CD53F fissure head diamond bur that was used in this study may good candidate for fissure preparation instrument and Garcia-Goddy et al. also recommended fissure type diamond point bur (Sorensen bur) [7]. From this result and previous those results, the fissure type diamond point may most acceptably instrument for invasive technique. The results of present study strongly suggested that the important factor for success of fissure sealant should select a case of proper fissure whether invasive technique is necessary or not. In case of performed invasive technique to immature occlusal fissure, minimal preparation of fissure pre-treatment is the key for safety and sufficiently good retention of fissure sealant.

\section{Conflicts of Interest}

There are no conflicts of interest.

\section{References}

1. Brown LJ, Kaste L, Selwitz R, Furman L (1996) Dental caries and sealant usage in U.S. children, 1988-1991: Selected findings from the Third National Health and Nutrition Examination Survey. JADA 127(3): 335343.
2. Carlos JP, Gittelsohn AM (1965) Longitudinal studies of the natural history of caries-II: A life-table study of caries incidence in the permanent teeth. Arch Oral Biol 10(5): 739-751.

3. Simonsen RJ (1987) Retention and effectiveness of a single application of white sealant after 10 years. JADA 115(1): 31-36.

4. Wendt LK, Koch G (1988) Fissure sealant in permanent first molars after 10 years. Swedish Dental Journal 12: 181-185.

5. Romcke RG, Lewis DW, Maze BD, Vickerson RA (1990) Retention and maintenance of fissure sealants over 10 years. JCDA 56(3): 235-237.

6. De craene GP, Martens C, Dermaut R (1988) The invasive pit-and -fissure sealing technique in pediatric dentistry: an SEM study of a preventive restoration. ASDC J Dent Child 55(1): 34-42.

7. Garcia Godoy F, De Araujo FB (1994) Enhancement of fissure sealant penetration and adaptation: The enameloplasty technique. J Clin Pediatr Dent 19(1): 13-18.

8. Xalabarde A, Garcia Godoy F, Boj JR, Canaida C (1996) Fissure micromorphology and sealant adaptation after occlusal enameloplasty. J Clin Pediatr Dent 20(4): 299-304.

9. Xalabarde A, Garcia Godoy F, Boj JR, Canaida C (1998) Microleakage of fissure sealants after occlusal enameloplasty and thermocycling. J Clin Pediatr Dent 22(3): 231-235.

10. Wright GZ, Hatibovic-Kofman S, Millenaar DW, Braverman I (1999) The safety and efficacy of treatment with air abrasion technology. Int J Paediatr Dent 9(2): 133-140.

11. Hatibovic Kofman S, Wright GZ, Braverman I (1998) Microleakage of sealants after conventional, bur, and air-abrasion preparation of pits and fissures. Pediatr Dent 20(3): 173-176.

12. Tirali RE, Celik C, Arhun N, Berk G, Cehreli SB (2013) Effect of laser and air abrasion pretreatment on the microleakage of a fissure sealant applied with conventional and self-etch adhesives. J Clin Pediatr Dent 37(3): 281-288.

13. Sancakli HS, Erdemir U, Yildiz E (2011) Effects of Er: YAG laser and air abrasion on the microleakage of a resin-based fissure sealant material. Photomed Laser Surg 29(7): 485-492.

14. Singla A, Garg S, Jindal SK, Suma Sogi HP, Sharma D (2011) In vitro evaluation of marginal leakage using invasive and noninvasive technique of light cure glass ionomer and flowable polyacid modified composite resin used as pit and fissure sealant. Indian J Dent Res 22(2): 205-209.

15. Gunjal S, Nagesh L, Raju HG (2012) Comparative evaluation of marginal integrity of glass ionomer and resin-based fissure sealants using invasive and non-invasive techniques: an in vitro study. Indian J Dent Res 23(3): 320-325.

16. Vineet D, Tandon S (2000) Comparative evaluation of marginal integrity of two new fissure sealants using invasive and non-invasive techniques: a SEM study. J Clin Pediatr Dent 24(4): 291-297.

17. Yamada Y, Hossain M, Shimizu Y, Kimura Y, Masuda Y, et al. (2008) Analysis of surface roughness and microleakage of fissure sealants following organic debris removal with Carisolv. J Dent 36(2): 130-137.

18. Garcia Godoy F and Medloch, JW (1988) An SEM study of the effects of air-polishing on fissure surfaces. Quintessence Int 19(7): 465-467.

19. Pope BD Jr, Garcia-Godoy F, Summitt JB, Chan DD (1996) Effectiveness of occlusal fissure cleansing methods and sealant micromorphology. ASDC J Dent Child 63(3): 175-180.

20. Taylor CL, Gwinnett AJ (1973) A study of the penetration of sealants into pits and fissures. J Am Dent Assoc 87(6): 1181-1188.

21. Paulo FK, Flavio Z, Maria Regina LS (1993) The immediate and long-term effects of invasive and noninvasive pit and fissure sealing techniques on the microflora in occlusal fissures of human teeth. Pediatri Dent 15(2): 108-112. 
22. De Craence GP, martens C and Demaut R (1988) The invasive pit-andfissure sealing technique in pediatric dentistry: An SEM study of a preventive restoration. ASDC J Dent Child 55(1): 34-42.

23. Le Bell Y and Forston L (1980) Sealing of preventively enlarged fissures. Acta Odontol Scand 38(2): 101-104.

24. Feldens EG, Feldens CA, de Araujo FB, Souza MA (1994) Invasive technique of pit and fissure sealants in primary molars: a SEM study. J Clin Pediatr Dent 18(3): 187-190.

25. Theodoridou Pahini S, Tolidis K, Papadogiannis Y (1996) Degree of microleakage of some pit fissure sealants: and in vitro study. Int J Paediatr Dent 6(3): 173-176.

26. Shapira J, Eidelman E (1986) Six-year clinical evaluation of fissure sealants placed after mechanical preparation: a matched pair study. Pediatr Dent 8(3): 204-205.
27. Shapira J, Eidelman E (1984) The influence of mechanical preparation of enamel prior to etching on the retention of sealants: three-year followup. J Pedod 8(3): 272-277.

28. Lygidakis NA, Oulis KI, Christodoulidis A (1994) Evaluation of fissure sealants retention following four different isolation and surface preparation techniques: four years clinical trial. J Clin Pediatr Dent 19(1): $23-25$

29. Blackwood JA, Dilley DC, Roberts MW, Swift EJ Jr (2002) Evaluation of pumice, fissure enameloplasty and air abrasion on sealant microleakage. Pediatr Dent 24(3): 199-203.

30. Welbury R, Raadal M, Lygidakis NA (2004) European Academy of Paediatric Dentistry. EAPD guidelines for the use of pit and fissure sealants. Eur J Paediatr Dent 5(3): 179-184.

\section{(c) (P) \\ This work is licensed under Creative Commons Attribution 4.0 License}

To Submit Your Article Click Here:

Submit Article

DOI: $10.32474 /$ IPDOAJ.2020.04.000187

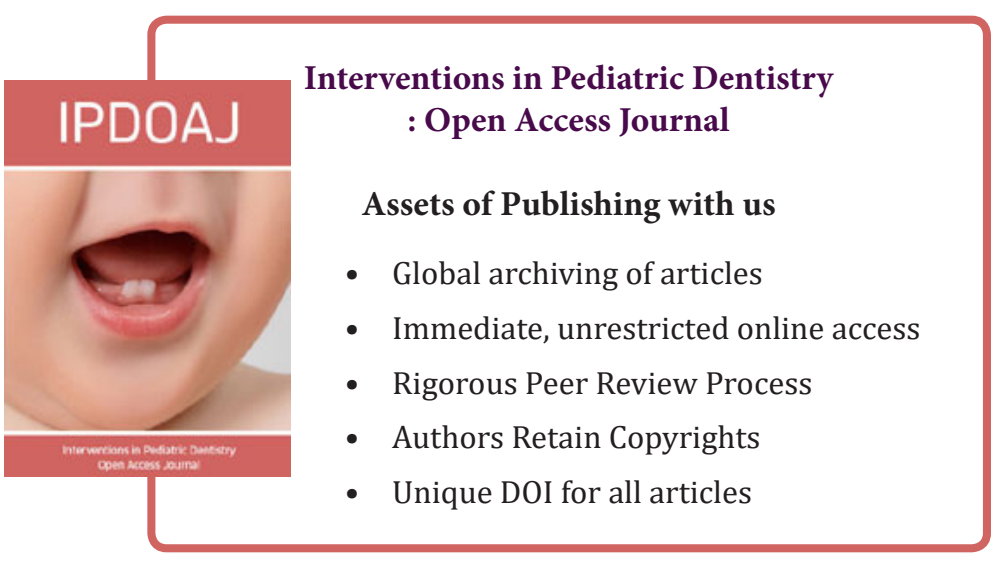

